\title{
Inglês como língua adicional na Educação Básica: reflexões sob a ótica Freiriana
}

\author{
Andrea da Silva Marques Ribeiro* \\ Jessica Fernandes Natarelli da Cruz ${ }^{* *}$
}

\begin{abstract}
Resumo
Com a nova redação dada à Lei de Diretrizes e Bases da Educação Nacional (Lei n 9394/96), o Inglês passou a ser a língua adicional obrigatória na Educação Básica; escolha, que anteriormente, ficava a cargo da comunidade escolar (BRASIL, 1996, 1998). Essa obrigatoriedade traz diversos prejuízos culturais e ideológicos em face ao papel hegemônico dos EUA no Continente Americano. No entanto, é inegável a importância do aprendizado de Língua Inglesa como instrumento de acesso aos bens culturais e a outras maneiras de ver o mundo (BRASIL, 1998; CRYSTAL, 2003; MOITA LOPES, 1996). Dentro dessa perspectiva, o Inglês como língua franca corrobora com a descolonização do idioma mais falado no mundo (LEFFA e IRALA, 2014; MOITA LOPES, 1996). Assim, diante da atual conjuntura do ensino de Língua Inglesa, surge a necessidade de se refletir sobre as práticas atuais que têm reforçado as desigualdades socais. Amparado nos pressupostos teóricos de Paulo Freire $(1967,1979,1987)$ e com base em pressupostos da pesquisa documental (GIL, 2008; MARCONI e LAKATOS, 2010), este artigo tem como objetivo fomentar reflexões sobre o ensino de Inglês como LA e, então, contribuir para a ressignificação do idioma na Educação Básica tendo em vista o seu papel como ferramenta de empoderamento dos alunos das classes populares em sua formação como cidadão crítico do mundo globalizado.
\end{abstract}

Palavras-chave: ensino de inglês, língua adicional, pedagogia crítica.

English as an additional language in Basic Education: reflections from Freire's perspective

\begin{abstract}
With the new writing given to the Law of Guidelines and Bases of National Education (Law 9394/96), English became the mandatory additional language in Basic Education; a choice which was previously made by school community (BRASIL, 1996, 1998). This obligation brings about several cultural and ideological damages vis-à-vis the hegemonic role of the USA in the American Continent. However, the importance of learning English, as an instrument to access cultural goods and other ways of seeing the world, is undeniable (BRAZIL, 1998; CRYSTAL, 2003; MOITA LOPES, 1996). In this perspective, English, as a global lingua franca, corroborates to the decolonization of the most widely spoken language in the world (LEFFA and IRALA, 2014; MOITA LOPES, 1996). Thus, concerning the present situation of English language teaching, there is a need to reflect on current practices that have reinforced social inequalities. Based on Paulo Freire's theoretical assumptions (1967, 1979, 1987) and based on assumptions of the documentary research (GIL, 2008, MARCONI and LAKATOS, 2010), this article aims to contribute to the re-signification of language teaching in Basic Education, considering its role as a tool for empowering students of popular classes in their learning process as a critical citizen of globalized world.
\end{abstract}

Keywords: english teaching, additional language, critical pedagogy.

*Professora adjunta do Programa de Pós-Graduação de Ensino em Educação Básica do Instituto de Aplicação Fernando Rodrigues da Silveira (PPGEB/CAp-UERJ) da Universidade do Estado do Rio de Janeiro. E-mail: andrea.marques@gmail.com.

** Mestranda do Programa de Pós-graduação de Ensino em Educação Básica (PPGEB/CAp-UERJ) e professora da Fundação Municipal de Educação de Niterói. E-mail: jenatarelli@ hotmail.com. 


\section{Introdução}

O presente artigo é fruto de nossas inquietações, como pesquisadoras e professoras de Inglês, frente às questões suscitadas pela legislação brasileira referente ao ensino de Língua Inglesa (doravante LI) na Educação Básica, principalmente no que concerne a obrigatoriedade do ensino do idioma em detrimento da escolha da comunidade escolar. Assim, com base nos pressupostos da pesquisa documental (GIL, 2008; MARCONI e LAKATOS, 2010), que inclui "os documentos de primeira mão" (GIL, 2008, p. 51) ou de "fonte primária" (MARCONI e LAKATOS, 2010, p. 157), partimos de documentos oficiais, tais como: a Lei $\mathrm{n}^{\mathbf{0}}$ 9.394/96, os Parâmetros Curriculares Nacionais de língua estrangeira e a Base Nacional Comum Curricular em um viés interpretativo-crítico com vistas a fomentar reflexões sobre o ensino de Inglês como língua adicional (LA), buscando, então, contribuir para discussões que venham ressignificar o ensino da língua na Educação Básica.

Na educação brasileira, a Lei de Diretrizes e Bases da Educação Nacional (LDB $n^{\circ}$ 9.394/96, art. 26, $\S 5^{\circ}$ ) determinam o ensino de uma LA no currículo da Educação Básica a partir do $6^{\circ}$ ano do Ensino Fundamental. Anteriormente, a língua adicional a ser oferecida era uma escolha da comunidade escolar (BRASIL, 1996, 1998). Porém, com a nova redação (Lei $n^{\circ}$ 13.415, de 2017), dada à LDB, em consequência das reformas propostas pela Base Nacional Comum Curricular (BRASIL, 2018), a LI passou a ser o idioma obrigatório, podendo ser ofertado um segundo no Ensino Médio.

Os currículos do Ensino Médio incluirão, obrigatoriamente, o estudo da Língua Inglesa e poderão ofertar outras línguas estrangeiras, em caráter optativo, preferencialmente o Espanhol, de acordo com a disponibilidade de oferta, locais e horários definidos pelos sistemas de ensino (BRASIL, LDB, art. 35, § $4^{\circ}, 1996$ ).

É inegável a importância do aprendizado de uma língua adicional na formação do cidadão crítico do mundo "[...] à medida que permite aos alunos entrar em contato com outras culturas, com modos diferentes de ver e interpretar a realidade" (BRASIL, 1998, p. 54). Logo, cada vez mais, surge a necessidade do desenvolvimento de novas habilidades para que o aluno possa participar das práticas de linguagem de um mundo globalizado. 


\begin{abstract}
Aprender a Língua Inglesa propicia a criação de novas formas de engajamento e participação dos alunos em um mundo social cada vez mais globalizado e plural, em que as fronteiras entre países e interesses pessoais, locais, regionais, nacionais e transnacionais estão cada vez mais difusas e contraditórias. Assim, o estudo da Língua Inglesa pode possibilitar a todos o acesso aos saberes linguísticos necessários para engajamento e participação, contribuindo para o agenciamento crítico dos estudantes e para o exercício da cidadania ativa, além de ampliar as possibilidades de interação e mobilidade, abrindo novos percursos de construção de conhecimentos e de continuidade nos estudos (BRASIL, 2018, p. 239).
\end{abstract}

Essa proposta para o ensino de Língua Inglesa, apresentada na Base Nacional Comum Curricular, não é muito diferente da orientada pelos Parâmetros Curriculares Nacionais para o ensino de Língua Estrangeira (PCN-LE). No entanto, pode-se considerar que a obrigatoriedade exclusiva do Inglês traz prejuízos consideráveis diante de um país, como o Brasil, inserido em um continente majoritariamente falante de Espanhol. A preferência pela LI em tal contexto pode ser justificada, atualmente, pelo fato de que os Estados Unidos mantêm papel hegemônico, como potência, dominante na política econômica, influenciando em diversas políticas sociais e culturais no mundo. Relações hegemônicas podem acarretar processos de aculturação e alienação que levam a um sentimento de não pertencimento à própria cultura. Nesse sentido, Freire (1979) destaca que "o ser alienado não procura um mundo autêntico. Isto provoca uma nostalgia: deseja outro país e lamenta ter nascido no seu. Tem vergonha da sua realidade. Vive em outro país e trata de imitá-la e se crê culto quanto menos nativo é." (FREIRE, 1979, p. 15). Segundo Crystal (2003), a posição hegemônica da Língua Inglesa resulta do poder econômico, oriundo de relações desiguais desde os tempos da colonização.

The present-day world status of English is primarily the result of two factors: the expansion of British colonial power, which peaked towards the end of the nineteenth century, and the emergence of the United States as the leading economic power of the twentieth century" (CRYSTAL, 2003, p. 6). ${ }^{1}$

Cabe salientar que não negamos a importância do Inglês como língua franca, pois de acordo com Crystal (2003, p. XIII), um idioma comum seria necessário para a compreensão mútua e cooperação internacional. Dessa maneira, é pensar na função

\footnotetext{
1"O status mundial atual do Inglês é principalmente o resultado de dois fatores: a expansão do poder colonial britânico, que atingiu o pico no final do século XIX, e o surgimento dos Estados Unidos como a principal potência econômica do século XX" (tradução nossa).
} 
social e política da língua adicional. Atualmente, a LI vem assumindo novas funções e um caráter comunicativo no mundo, o que dialoga com a visão de língua franca. Sendo assim, negar o ensino de Inglês é deixar de fornecer as ferramentas para que o aluno tenha acesso aos bens culturais e a outras maneiras de ver o mundo, colaborando para o seu processo de humanização e transformação da realidade. De acordo com Paulo Freire (1967, 1987), o ser humano é sujeito da construção da sua cultura, estabelecendo relações com o mundo por meio da linguagem. Entendendo que língua também é cultura, o ser humano procura compreender a sua realidade através da palavra, resultando na construção de seu conhecimento de mundo. Então, para entender o mundo, o ser humano precisaria dominar a palavra dado que ele se redescobriria " [...] como sujeito de todo o processo histórico da cultura e, obviamente, também da cultura letrada. O que o homem fala e escreve e como fala e escreve, tudo é expressão objetiva de seu espírito" (FIORI apud FREIRE, 1987, p. 6). Ao tomar conhecimento da sua realidade, superando as "situações-limite", que o impedem de transformá-la, o ser humano ultrapassa as barreiras da transitividade ingênua, alcançando a transitividade crítica, a transformação de sua realidade (FREIRE, 1967, 1987). "Eles não aprendem Português quanto mais Inglês" (MOITA LOPES, 1996, p. 64) ${ }^{2}$ expressa uma das "situações-limite", fatos como determinantes históricos, a ser superada pelo ensino de Língua Inglesa no contexto da escola pública uma vez que essa crença na falta de aptidão dos alunos para aprender um novo idioma é vista como uma barreira para que docentes e discentes possam alcançar a sua humanização. Embora esses sujeitos reconheçam a desigualdade perante à oferta do ensino de LA entre a educação pública e privada, eles não se sentem responsáveis por transformar a sua realidade. Isso posto, diante de um ensino de línguas, no qual os professores tendem a organizar os conteúdos de maneira simplificada, apresentando a língua através de palavras descontextualizadas e isoladas, além de priorizar a memorização de vocabulário, na tentativa de facilitar a aprendizagem (BRASIL, 1998), a falta de uma concepção crítica da linguagem serve de instrumento de manobra para a manutenção da alienação do cidadão. Portanto, o professor, como trabalhador social, tem o compromisso com o processo de transformação da realidade.

\footnotetext{
${ }^{2}$ Fala retirada do livro Oficina de Linguística Aplicada, no qual Moita Lopes (1996, p. 64) apresentou dados de pesquisa sobre uma avaliação de um programa de ensino de Língua Inglesa nas escolas municipais do Rio de Janeiro.
} 
Na ação que provoca uma reflexão que se volta a ela, o trabalhador social irá detectando o caráter preponderante da mudança ou estabilidade, na realidade social na qual se encontra. Irá percebendo asforças que na realidade social estão com a mudança e aquelas que estão com a permanência (FREIRE, 1979, p. 21).

Destarte, o ensino de uma língua adicional precisa estar respaldado por concepções de ensino que possam promover processos de letramento crítico a fim de contribuir para o engajamento do aluno e de suas relações com o outro, para que ele possa agir no mundo social.

\section{Relevância do aprendizado de uma língua adicional na Educação Básica}

A língua adicional tem o papel de proporcionar ao aluno acesso ao conhecimento, tornando-o parte de um mundo plurilíngue e pluricultural, além de fornecer as ferramentas necessárias para a formação acadêmica e profissional, conforme já apontado nos PCN-LE, "para que as pessoas tenham acesso mais igualitário ao mundo acadêmico, ao mundo dos negócios e ao mundo da tecnologia [...]” (BRASIL, 1998, p. 38).

Além disso, Moita Lopes (1996, p. 132) atenta para o fato de que aprender uma LA auxilia no desenvolvimento da habilidade de leitura em língua materna. Ainda para os PCN-LE (BRASIL, 1998), o caráter metacognitivo da língua adicional pode contribuir para o desenvolvimento da consciência linguística e para o aumento do nível de letramento do aluno, que

Leva a uma nova percepção da natureza da linguagem, aumenta a compreensão de como a linguagem funciona e desenvolve maior consciência do funcionamento da própria língua materna. Ao mesmo tempo, ao promover uma apreciação dos costumes e valores de outras culturas, contribui para desenvolver a percepção da própria cultura por meio da compreensão da(s) cultura(s) estrangeira(s) (BRASIL, 1998, p. 37).

Os Parâmetros Curriculares Nacionais para o ensino de língua estrangeira (BRASIL, 1998) apresentam três critérios para a inclusão de uma língua adicional no currículo da Educação Básica: os fatores históricos, os fatores relativos à comunidade local e os fatores relativos à tradição. $O$ primeiro fator refere-se à função que um determinado idioma exerce na história da humanidade, determinado a sua relevância. $\mathrm{O}$ 
segundo leva em consideração a convivência entre as comunidades locais, justificando a necessidade de uma língua para o estabelecimento das relações. Já o último fator tem relação com a cultura, concebendo a língua como acesso ao conhecimento da história de um país. Nesse sentido, se pensarmos na configuração geopolítica da América do Sul, a aprendizagem de Espanhol e de Português pode ser também bastante significativa social e culturalmente.

A aprendizagem do Espanhol no Brasil e do Português nos países de Língua Espanhola na América é também um meio de fortalecimento da América Latina, pois seus habitantes passam a se (re)conhecerem não só como uma força cultural expressiva e múltipla, mas também política (um bloco de nações que podem influenciar a política internacional) (BRASIL, 1998, p. $50)$.

No entanto, atualmente, em nossa legislação educacional brasileira, há a obrigatoriedade do ensino da Língua Inglesa somente, com exceção do Ensino Médio, no qual é possível escolher mais uma língua adicional (BRASIL, 1996). Ressaltamos que na redação anterior da LDB (BRASIL, Lei n 9394/96), na parte diversificada do currículo, era obrigatório, a partir do $6^{\circ}$ ano, “[...] o ensino de pelo menos uma língua estrangeira moderna, cuja escolha ficará a cargo da comunidade escolar, dentro das possibilidades da instituição". Independentemente dessa posição imperialista, "o Inglês, hoje, é a língua mais usada no mundo dos negócios, e em alguns países, como Holanda, Suécia e Finlândia, seu domínio é praticamente universal nas universidades" (BRASIL, 1998, p. 23). Nesse caso, a atribuição do conceito de língua franca à LI, que será tratado na seção seguinte, leva ao entendimento de que ela não pertence exclusivamente a um único território, perdendo o seu caráter estrangeiro e hegemônico, o que permite a valorização dos usos dos falantes do mundo.

Em outras palavras, ao invés da abordagem integrativa com a cultural estrangeira, faz-se uso do Inglês como língua internacional que serve como instrumento de comunicação entre os povos. Não é, portanto, ignorar a língua do imperialista, mas saber fazer uso dela em benefício do Terceiro Mundo o que se advoga aqui (MOITA LOPES, 1996, p. 59).

Para que isso seja possível, é necessário que a LA esteja atrelada a sua função social. Por conseguinte, o letramento crítico surge da necessidade de se desvelar os 
valores, as intenções e as ideologias presentes no discurso (ROJO, 2009), formando o cidadão crítico e reflexivo sobre o seu papel na sociedade global.

\section{Língua Inglesa: segunda língua, estrangeira, franca, global ou adicional?}

De acordo com Crystal (2003, p. 3), uma língua atinge o status de global quando ela apresenta um papel de relevância reconhecido mundialmente. Para isso, há dois caminhos: primeiro, o idioma poderia tornar-se o oficial de um país “[...] para ser usado como um meio de comunicação em domínios como o governo, os tribunais, a mídia e o sistema educacional" (CRYSTAL, 2003, p. 4). ${ }^{3}$ Desse modo, ele seria considerado a segunda língua, um complemento da materna em função das necessidades linguísticas daquela comunidade. O segundo caminho é em relação aos critérios que fazem com que uma língua seja a estrangeira ensinada nas escolas, como tradição, cooperação política e econômica, interação cultural, comercial e tecnológica (CRYSTAL, 2003). Ademais, o autor salienta os motivos pelos quais o Inglês se tornou uma língua global, internacional ou franca. A LI é a oficial ou tornou-se a segunda língua em mais de 70 países, além de um quarto do mundo ser fluente no idioma (CRYSTAL, 2003).

\footnotetext{
English is now the language most widely taught as a foreign language - in over 100 countries, such as China, Russia, Germany, Spain, Egypt and Brazil - and in most of these countries it is emerging as the chief foreign language to be encountered in schools, often displacing another language in the process (CRYSTAL, 2003, p. 5). ${ }^{4}$
}

O caráter internacional de uma língua franca não pressupõe que haja uma unidade no discurso, mas que sejam consideradas as diferentes variações linguísticas existentes ao redor do mundo. À vista disso, a necessidade surge da "[...] conveniência de ter uma língua franca disponível para servir às necessidades e relações globais [...]" (CRYSTAL, 2003, p. 30). ${ }^{5}$ Sendo assim, é valorizar a função social e política que uma língua exerce na interação global.

\footnotetext{
3 " [...] to be used as a medium of communication in such domains as government, the law courts, the media, and the educational system" (tradução nossa).

4"Inglês é agora a língua mais amplamente ensinada como língua estrangeira - em mais de 100 países, tais como China, Rússia, Alemanha, Espanha, Egito e Brasil - e na maioria desses países está emergindo como a principal língua estrangeira a ser encontrada nas escolas, muitas vezes deslocando outra língua no processo" (tradução nossa).

5 "[...] convenience of having a lingua franca available to serve global human relations and needs $[\ldots]$ " (tradução nossa).
} 
Esse entendimento favorece uma educação linguística voltada para a interculturalidade, isto é, para o reconhecimento das (e o respeito às) diferenças, e para a compreensão de como elas são produzidas nas diversas práticas sociais de linguagem, o que favorece a reflexão crítica sobre diferentes modos de ver e de analisar o mundo, o(s) outro(s) e a si mesmo. (BRASIL, 2018, p. 240)

Estudos recentes da Linguística Aplicada têm abordado um novo conceito para a língua estrangeira, que passaria a ser chamada de língua adicional. A palavra "estrangeira" remete a algo totalmente externo ao sujeito. Tanto a Língua Inglesa quanto a Espanhola fazem parte do cotidiano dos aprendizes de diferentes formas se considerarmos o mundo globalizado e o acesso aos bens e produções culturais. $\mathrm{O}$ caráter estrangeiro de uma língua ressalta a distância desta com a realidade dos alunos, ignorando inclusive aspectos da língua materna que auxiliam na aprendizagem de outro idioma. Assim, o ensino de Espanhol e de Inglês nas escolas brasileiras precisa considerar práticas discursivas tanto nesses idiomas quanto na língua materna. Nessa perspectiva, o aprendizado de uma LA seria desenvolvido a partir, principalmente, da língua materna do aluno (LEFFA e IRALA, 2014, p. 33), ou seja, é adicionar uma nova língua na comunicação daqueles que já conhecem pelos menos uma, caracterizando o que se entende por língua adicional.

\section{A pedagogia crítica de Paulo Freire e o ensino de línguas adicionais}

Para Paulo Freire (1967, 1979, 1987), a educação tem como objetivo o processo de transformação da realidade, no qual, o aluno, atingindo a consciência crítica, reconhece o seu papel de oprimido, lutando para alcançar a sua liberdade e humanização. Nesse caso, o papel da língua adicional é de elevar esse objetivo a nível global.

Entretanto, o caráter global de um idioma pode trazer prejuízos ideológicos, culturais e políticos para a sociedade, pois “[...] uma língua global cultivará uma classe linguística monolíngue de elite, mais complacente e desdenhosa em suas atitudes em relação a outras línguas" (CRYSTAL, 2003, p. 14-15). Não negando a necessidade de uma língua adicional, é preciso descolonizar os aspectos que fazem com que um determinado idioma opere no apagamento da identidade do outro. Um desses aspectos seria o papel hegemônico do Inglês, por exemplo, principalmente em relação às correções linguísticas, fazendo com que haja um único acento correto. 
Neste sentido, em si mesma, esta realidade é funcionalmente domesticadora. Libertar-se de sua força exige, indiscutivelmente, a emersão dela, a volta sobre ela. É por isso que só através da práxis autêntica que, não sendo "blablablá", nem ativismo, mas ação e reflexão, é possível fazê-lo. (FREIRE, 1987, p. 16)

A função de uma pedagogia crítica é operar na mudança da supervalorização de uma determinada língua, consequentemente, da cultura do estrangeiro, o que não significa ser refratário ou ignorar a cultura do outro. Portanto, o problema reside no fato do desejo de pertencer à outra cultura. Por esse ângulo, Paulo Freire (1979, p.15) enfatiza que "o erro não está na imitação, mas na passividade com que se recebe a imitação ou na falta de análise ou de autocrítica". Cabe ressaltar que o ensino de uma LA contribui de maneira significativa para um dos objetivos do Ensino Fundamental, que é o desenvolvimento do posicionamento crítico do aluno em relação às diferenças culturais, sociais, de gênero e de etnia ao conhecimento dos aspectos socioculturais de outros povos, valorizando a sua própria cultura (BRASIL, 1998, p. 7). Kumaravadivelu (2003), alinhado às teorias de Paulo Freire, aborda uma nova pedagogia para o ensino de línguas, o Pós-Método, propondo três parâmetros para que seja possível a descolonização: o parâmetro da particularidade, o parâmetro da praticidade e o parâmetro da possibilidade. O primeiro considera as particularidades da comunidade local numa pedagogia sensível à subjetividade por meio da observação-reflexão-ação, permitindo que o professor elabore teorias a partir da prática, o que rompe com a verticalização educacional entre a academia e a escola, para alcançar o parâmetro da praticidade. $\mathrm{O}$ último refere-se às práticas que possam levar os alunos a transgredirem da sua condição de oprimido. Por conseguinte, "no processo de sensibilização para a realidade sociopolítica vigente, o parâmetro da possibilidade também se preocupa com a identidade individual” (KUMARAVADIVELU, 2003, p. 36). ${ }^{6}$ À vista disso, o aprendizado de uma LA estaria atrelado ao empoderamento do aluno. Caberia, então, ao professor, como profissional social, o compromisso com práticas de linguagem que possam contribuir para a mudança da realidade. Dessa maneira, ele não pode ser neutro, até mesmo passivo, frente às demandas sociais que visam a libertação e a humanização

\footnotetext{
6"In the process of sensitizing itself to the prevailing sociopolitical reality, the parameter of possibility is also concerned with individual identity" (tradução nossa).
} 
do ser oprimido, sendo sujeito ativo desse processo, tomado de consciência da realidade (FREIRE, 1979).

No entanto, no atual cenário do ensino de línguas adicionais na educação pública brasileira, embora seja um direito, aprender um idioma ainda parece ser um privilégio da elite.

\begin{abstract}
Embora seu conhecimento seja altamente prestigiado na sociedade, as línguas estrangeiras, como disciplinas, se encontram deslocadas da escola. A proliferação de cursos particulares é evidência clara para tal afirmação. Seu ensino, como o de outras disciplinas, é função da escola, e é lá que deve ocorrer. As oportunidades de aprender línguas nos Centros de Línguas das redes oficiais, existentes em algumas partes do Brasil, são entendidas como suplementares à oferta de língua estrangeira dentro do currículo, no sentido de que outras línguas, além daquela incluída na rede escolar, possam ser também aprendidas (BRASIL, 1998, p. 19).
\end{abstract}

Nessa perspectiva, os cursos de idiomas também podem ser entendidos como suplementares à oferta das línguas adicionais presentes no currículo da Educação Básica tendo em vista que nem sempre as escolas conseguem atender às demandas do ensino de idiomas. Fatores como a carga horária reduzida, o grande número de alunos por turma, pouco domínio das habilidades linguísticas pelos professores e ausência de suportes didáticos, além da crença da falta de aptidão linguística das classes populares para aprender um idioma (MOITA LOPES, 1996, p. 67 e 132), contribuem para a ideia de que não é possível aprender uma língua adicional na escola pública.

a mercantilização e/ou 'mercadologização' da educação, onde o sucesso de
um sistema preconiza a ruína do outro, o discurso que se solidifica dá
margem a verdadeiras aberrações que, por exemplo, atribuem a incapacidade
dos alunos de escola pública de aprender Inglês ou outra LE [língua
estrangeira] à condição socioeconômica, déficit linguístico, déficit cultural,
etc. (SIQUEIRA, 2014, p. 100).

Consequentemente, por meio do controle do saber, que se manifesta através da falta de investimento em políticas públicas de ensino de LA no contexto da escola pública, o opressor utiliza táticas ardilosas para que o oprimido não se reconheça como tal, uma vez que aprender uma LA ainda é reservado à classe dominante. Com isso, entendemos que a aprendizagem de outras línguas vai além de aspectos relacionados a maiores oportunidades de inserção no mercado de trabalho e de formação continuada através dos programas de Pós-graduação, pois oportuniza o acesso à informação e aos 
bens culturais da humanidade, trazendo perspectivas mais críticas e dialógicas às experiências escolares e cotidianas. No contexto do ensino de línguas, a opressão se manifesta e se concretiza em práticas pedagógicas e técnicas de ensino descontextualizados e desmotivadores, desconectados, enfim, da realidade dos alunos. Hoje, há um crescimento na expansão do ensino de Inglês para os primeiros anos do Ensino Fundamental nas redes públicas e privadas de ensino, ainda que de forma desigual conforme apontam Tílio e Rocha (2009, p. 296): “apesar da natureza facultativa do ensino de LI nas séries iniciais do Ensino Fundamental (EF) brasileiro, presenciamos a sua consolidação no setor privado e a seu crescente, porém irregular, expansão no setor público". Logo, a ausência de legitimidade para esse segmento acarreta diversos prejuízos para a disciplina no contexto da escola pública, como a falta de diretrizes nacionais, de políticas públicas e de um Programa Nacional de Livro Didático (PNLD), intensificando ainda mais as desigualdades sociais.

Haja vista, nessa lógica, para Freire (1979), uma sociedade fechada é caracterizada pelo autoritarismo, pela antidialogicidade e pela verticalidade das relações sociais. Dentro da perspectiva do ensino de Inglês no âmbito da educação pública, a ação antidialógica, ou seja, a falta de diálogo e a imposição de valores, é um instrumento para que o sistema opere na desarmonia entre os sujeitos desse contexto, gerando um jogo de culpabilização para justificar o "inédito viável”, situações que pela crença são impossíveis de acontecer, de que Língua Inglesa na escola pública não funciona. Desse modo, o seu principal objetivo seria o de manter a ordem de classes, na qual haveria sempre oprimidos a serviço de seus opressores. Para isso, não são fornecidas as ferramentas para que possa haver uma mobilidade social e econômica. A ameaça para esse modelo de sociedade estaria na desalienação dos sujeitos. Então, uma sociedade em transição entre a alienação e a libertação (humanização) surgiria do processo de dar poder ao povo e na construção de novos valores.

\section{Reflexões finais}

Diante da atual conjuntura do ensino de línguas adicionais na educação pública brasileira, surge a necessidade de se repensar as práticas de linguagem a fim de promover um processo de aprendizagem voltado para a formação do aluno como ser humano, capaz de refletir sobre as suas ações no mundo de maneira crítica. 
No processo de colonização, desenvolvemos uma admiração pelo que é estrangeiro. Dessa maneira, Paulo Freire (1979) alerta que o educador, diante do seu compromisso com a sociedade, precisa escolher a sua opção: se contribui para o processo de transformação social ou se fica a favor da permanência atual da realidade que lhe é imposta. Assim, ao selecionar suas técnicas de ação, ele pode reforçar ou romper com a transplantação de valores e comportamentos impostos pelo opressor.

\begin{abstract}
A sociedade alienada não tem consciência de seu próprio exigir. Um profissional alienado é um ser inautêntico. Seu pensar não está comprometido consigo mesmo, não é responsável. O ser alienado não olha para a realidade com critério pessoal, mas com olhos alheios. Por isso vive uma realidade imaginária e não a sua própria realidade objetiva. Vive através da visão de outro país. Vive-se Rússia ou Estados Unidos, mas não se vive Chile, Peru, Guatemala ou Argentina (FREIRE, 1979, p. 15).
\end{abstract}

Embora a imposição de uma LA no currículo possa transparecer um posicionamento imperialista, é inegável a necessidade de uma língua franca em prol da construção das relações em nível global. Ademais, ao aprender um idioma, o aluno passa a ter acesso aos bens culturais da humanidade. Negar esse conhecimento é manter uma estrutura social sem mobilidade econômica, promovendo a alienação do oprimido a serviço do opressor. No entanto, atualmente, há diversas "situações-limites", que impendem a sua humanização, conforme afirma Freire (1987, p. 48), das quais “[...] se apresentam aos homens como se fossem determinantes históricas, esmagadoras, em face das quais não lhes cabe outra alternativa senão adaptar-se" (FREIRE, 1987, p. 48).

Destarte, o ensino de língua adicional, como prática da liberdade, propõe a descolonização e a desestrangeirização do idioma a ser ensinado para que ele sirva de instrumento de empoderamento do oprimido para a transformação da realidade. Em tal contexto, o desafio se coloca em promover oportunidades significativas de aprender LI na escola de modo a garantir o acesso a bens culturais da humanidade, mas, ao mesmo tempo, oportunizar o acesso às demais línguas que sejam importantes para as diferentes comunidades. Assim sendo, é necessário enfatizar o papel da comunidade na escolha das línguas a serem ofertadas para atender às necessidades locais e globais das diferentes realidades das comunidades escolares. Nessa perspectiva, colocam-se diferentes desafios para o ensino de Inglês como LA na Educação Básica. Tais desafios englobam diferentes aspectos, que vão da concepção de língua e de aprendizagem que 
54 Polyphonía, v. 30/1, jan./jun. 2019

permeiam as práticas escolares a questões de políticas públicas que consigam atender às diversidades locais e, ao mesmo tempo, atender às demandas trazidas pela globalização, na qual a Língua Inglesa pode funcionar como instrumento de libertação ou de alienação.

\section{Referências}

BRASIL. Lei de Diretrizes e Bases da Educação Nacional. Lei Federal n ${ }^{\circ} 9.394$ de 20 de dezembro de 1996 estabelece as Diretrizes e Bases da Educação Nacional. Brasília: MEC, 1996.

- Parâmetros curriculares nacionais: terceiro e quarto ciclos do ensino fundamental: língua estrangeira. Brasília: MEC/SEF, 1998.

Base Nacional Comum Curricular. Brasília: MEC, 2018. Disponível em: http://basenacionalcomum.mec.gov.br/wp-content/uploads/2018/02/bncc-20dezsite.pdf. Acesso em: 07 jun. 2018.

CRYSTAL, David. English as a global language. New York: Cambridge University Press, 2003.

FREIRE, Paulo. Educação como prática da liberdade. Rio de Janeiro: Paz e Terra, 1967.

. Educação e mudança. Rio de Janeiro: Paz e Terra, 1979.

Pedagogia do oprimido. Rio de Janeiro: Paz e Terra, 1987.

GIL, Antônio Carlos. Métodos e técnicas de pesquisa social. 6 ed. São Paulo: Editora Atlas SA, 2008.

KUMARAVADIVELU, B. Beyond methods: macrostrategies for language teaching. Londres: Yale University Press, 2003.

LEFFA, Vilson José; IRALA, Valesca Brasil. O ensino de outra(s) língua(s) na contemporaneidade: questões conceituais e metodológicas. In: LEFFA, Vilson José; IRALA, Valesca Brasil (Org.). Uma espiadinha na sala de aula: ensinando línguas adicionais no Brasil. Pelotas: Educat, 2014, p. 21-48.

LAKATOS, Eva Maria; MARCONI, Marina de Andrade. In: Fundamentos de metodologia científica, v. 7, 2010.

MOITA LOPES, Luiz Paulo. Oficina de linguística aplicada. Campinas: Mercado de Letras, 1996.

ROXANE, Rojo. Letramentos múltiplos, escola e inclusão social. São Paulo: Parábola, 2009. 
SIQUEIRA, Sávio. O Ensino de Inglês na escola pública: do professor postiço ao professor mudo, chegando ao professor crítico-reflexivo. In: LIMA, Diógenes Cândido de (Org.). Inglês em escola pública não funciona? Uma questão de múltiplos olhares. São Paulo: Parábola, 2014, p. 93-110.

TÍLIO, Rogério; ROCHA, Cláudia Hilsdorf. As dimensões da linguagem em livros didáticos para o Ensino Fundamental I. In: Trabalhos em Linguística Aplicada, v. 2, n. 48. São Paulo: UNICAMP, Jul./Dez. 2009, p. 295-315. Disponível em: http://www.scielo.br/pdf/tla/ v48n2/08.pdf. Acesso em: 13 jun. 2018. 